\title{
The association between objective walkability, neighborhood socio-economic status, and physical activity in Belgian children
}

\author{
Sara D'Haese ${ }^{1,2^{*}}$, Delfien Van Dyck ${ }^{1,2}$, Ilse De Bourdeaudhuij ${ }^{1}$, Benedicte Deforche ${ }^{1,3}$ and Greet Cardon ${ }^{1}$
}

\begin{abstract}
Background: Objective walkability is an important correlate of adults' physical activity. Studies investigating the relation between walkability and children's physical activity are scarce. However, in order to develop effective environmental interventions, a profound investigation of this relation is needed in all age groups. The aim of this study was to investigate the association between objective walkability and different domains of children's physical activity, and to investigate the moderating effect of neighborhood socio-economic status in this relation.

Methods: Data were collected between December 2011 and May 2013 as part of the Belgian Environmental Physical Activity Study in children. Children (9-12 years old; $n=606)$ were recruited from 18 elementary schools in Ghent (Belgium). Children together with one of their parents completed the Flemish Physical Activity Questionnaire and wore an accelerometer for 7 consecutive days. Children's neighborhood walkability was calculated using geographical information systems. Multilevel cross-classified modeling was used to determine the relationship between children's PA and objectively measured walkability and the moderating effect of neighborhood SES in this relation.
\end{abstract}

Results: In low SES neighborhoods walkability was positively related to walking for transportation during leisure time ( $\beta=0.381 \pm 0.124 ; 95 \% \mathrm{Cl}=0.138,0.624)$ and was negatively related to sports during leisure time $(\beta=-0.245 \pm 0.121$; $95 \% \mathrm{Cl}=-0.482,-0.008)$. In high socio-economic status neighborhoods, walkability was unrelated to children's physical activity. No relations of neighborhood walkability and neighborhood socio-economic status with cycling during leisure time, active commuting to school and objectively measured moderate- to vigorous-intensity physical activity were found.

Conclusions: No univocal relation between neighborhood walkability and physical activity was found in 9-12 year old children. Results from international adult studies cannot be generalized to children. There is a need in future research to determine the key environmental correlates of children's physical activity.

Keywords: GIS, Exercise, Physical environment, Youth, Walking, Cycling, Neighborhood, Children, Activity

\section{Background}

Although physical activity (PA) is associated with health benefits [1], many children do not meet the PA guidelines of 60 minutes of daily moderate- to vigorous-intensity physical activity (MVPA) [2]. In order to develop effective interventions to promote children's PA, insight into potential determinants of PA is necessary [3].

\footnotetext{
* Correspondence: Sara.DHaese@UGent.be

'Faculty of Medicine and Health Sciences, Department of Movement and Sports Sciences, Ghent University, Watersportlaan 2, Ghent 9000, Belgium ${ }^{2}$ Research Foundation Flanders (FWO), Egmontstraat 5, Brussels 1000, Belgium

Full list of author information is available at the end of the article
}

Ecological models state that besides individual factors, environmental factors (e.g. physical environment) can influence PA behaviors [4] directly as well as indirectly [5]. These theories suggest a profound investigation of the neighborhood environment in order to create suitable interventions.

Walkability is a thoroughly studied physical environmental factor in relation to adults' PA [6]. A high walkable neighborhood is characterized by high residential density, high street connectivity and high land use mix diversity [7]. In studies from the USA, Australia and Europe, higher objectively measured walkability has been 
consistently related to higher PA levels and more active transportation in adults [8-11]. It is important to find out if walkability is similarly related to PA in other age groups besides adults, because neighborhood physical environmental interventions affect all inhabitants of a neighborhood, and not only adults. In Belgium, the relation between objectively measured walkability and PA has been investigated in adults $(20-65 \mathrm{yr})$, adolescents $(13-15 \mathrm{yr})$, and older adults $(>65 \mathrm{yr})$. Also the moderating effect of neighborhood socio-economic status (SES) in the relation between walkability and PA was investigated in these age groups. Investigating this moderating effect is important, as the known health disparities across socio-economic groups [12] need to be reduced. Therefore, it is essential to investigate whether walkability is positively related to children's physical activity in low SES neighborhoods. If a positive relation can be found, this can be promising for potential future interventions with a focus on children from low SES neighborhoods.

In Belgian adults, objectively measured walkability was positively associated with accelerometer-based MVPA, transport-related walking and cycling and recreational walking. No interactions between walkability and neighborhood SES were found [9]. In Belgian adolescents, objectively measured neighborhood walkability was positively associated with accelerometer-MVPA and the average activity level (counts/min), but only in low SES neighborhoods. In Belgian older adults, objectively measured walkability was positively related to transportrelated walking. Furthermore, walkability was positively related to accelerometer-based MVPA [13]. As these studies investigated these relationships in the same neighborhoods, results in different age groups are comparable.

Based on these Belgian studies it can be concluded that objectively measured walkability is differently related to PA in different age groups $[9,14]$; but until now, no results on these associations are available in children. As physical environmental interventions can affect large groups of people at the same time, there is a strong need to investigate the association between objectively measured walkability and children's PA before intervening in the environment.

Some international studies already investigated the relation between objectively measured walkability and children's active transportation. Positive relations have been reported between school walkability and children's active transportation to school in Denmark [15], Australia $[16,17]$ and Canada [18]. One study investigated home neighborhood walkability in relation to active transportation to school in 5-18 year-old children in the USA [19]. In that study, walkability was positively related to children's active transportation to school, only in high SES neighborhoods [19]. No European studies investigating the relation between objectively measured neighborhood walkability and children's PA could be located in the literature; so there is a need for European studies investigating this relation.

The aim of this study was to investigate the association between objective neighborhood walkability and PA, and the possible moderating effects of neighborhood SES in this relation in Belgian children. This study is unique as the results will enable us to compare the differences in the relation between walkability and PA across different age groups in the same city.

\section{Methods \\ Procedure}

Data were collected between December 2011 and May 2013 as part of the Belgian Environmental Physical Activity Study in children (BEPAS-child). Principals $(\mathrm{n}=46)$ from primary schools in Ghent (237000 inhabitants, $15685 \mathrm{~km}^{2}$ ) were asked to participate in the study. In total, 18 agreed and gave written informed consent (response rate $=34.6 \%$ ). Children and their parents from fourth, fifth and sixth grade were informed $(n=994)$ about the study and 606 parents gave written informed consent (response rate $=61.0 \%$ ). Of these 606 children, 112 children were excluded as no objectively measured walkability data were available (69 children did not live in Ghent and parents of 43 children did not fill out children's home address in the questionnaire).

Children were asked to wear an accelerometer for 7 consecutive days, to fill out a questionnaire at school and one of the parents was asked to fill out a questionnaire together with his/her child. The Ethics Committee of the Ghent University Hospital approved the study.

\section{Measurements \\ Demographic variables}

Sex was derived from the children's questionnaire that was filled out in the classroom. Children's age was derived from the parental questionnaire. Educational attainment was used as a proxy for family SES, as educational attainment is easy to measure and is fairly stable beyond early adulthood. Furthermore, higher levels of education are usually associated with better jobs, housing, neighborhoods, working conditions and higher incomes [20]. Parents were asked to report their own and their partner's level of education (response options: primary school education, vocational secondary education, technical secondary education, general secondary education or art secondary education, college education or university education). Educational attainment was used as a proxy for family SES. Families were classified as high SES-families if the educational level of at least one parent was of a college or university education level; otherwise they were classified as low SES families. 


\section{Physical activity}

Children's self-reported PA was measured with the Flemish Physical Activity Questionnaire (FPAQ). Parents were asked to fill out the questionnaire at home together with their children and to report their child's PA levels in a usual week. This questionnaire has been shown to be a reliable and reasonably valid instrument to assess different dimensions of PA in children, especially when completed with parental assistance [21]. The test-retest ICC's ranged from 0.74 to 0.93 , with exception from ICC $=0.26$ for active transportation during leisure time. Concurrent validity ranged from $r=0.27$ to $r=0.44$ [21] The number of minutes per day of walking for transport during leisure time, cycling for transport during leisure time, active transportation to school and sports during leisure time were derived from the questionnaire. An outline of the questionnaire is added as in Additional file 1.

Objective PA was determined by accelerometers. Children wore an Actigraph $^{\mathrm{Tm}}$ GT1M, GT3X or GT3X + accelerometer (15 s epoch) during waking hours for 7 consecutive days. Strong agreement was found between these three activity monitors for measuring MVPA in children [22], making it acceptable to use different models within a given study. The accelerometer was worn on the right hip. Accelerometer data were screened, cleaned and scored using data-reduction software MeterPlus 4.2. Periods of 20 minutes of consecutive zeros or more were removed and defined as non-wear time. Non-wear time activity diaries were provided to register activities for which the accelerometer was removed (e.g. bathing, swimming) and were used to replace the consecutive number of zeros by the corrected number of minutes MVPA [23]. MVPA was calculated using the cutpoints of Evenson [24]. These cutpoints were recommended in a comparative validity study of accelerometer cutpoints [25]. Children were included in the study if they had at least 2 weekdays with minimum $10 \mathrm{~h}$ wearing time or 1 weekend day with minimum 8 h wearing time [26].

\section{Neighborhood variables}

Neighborhood SES Ghent consists of 201 statistical sectors, these are the smallest administrative entities for which statistical data, are available. Children included in the present study lived in 109 different statistical sectors. Median annual household income data (National Institute of Statistics-Belgium, 2008) were used to determine neighborhood SES of the different statistical sectors. Neighborhoods were characterized as low SES (income $<€ 22,359$ ) or high SES (income $\geq € 22,359$ ) based on the median.

Walkability Objective neighborhood walkability of all statistical sectors was calculated using a geographical information system database. Geographical data were obtained from the Service for Environmental Planning in Ghent.

Residential density, intersection density and land use mix diversity were determined and $\mathrm{z}$-scores were calculated. Walkability was calculated as follows: walkability $=\left(2^{*} \mathrm{z}-\right.$ connectivity $)+($ z-residential density $)+(z$-land use mix $)$. This formula is an adapted version of the formula of Frank and colleagues [27]. Because no data of 'retail floor area' were available, this was omitted from the original formula. Residential density was calculated using the ratio of residential units to the land area devoted to residential use in each neighborhood. Connectivity in each neighborhood was represented by the ratio of the number of intersections (3 or more streets) to the land area. Land use mix indicated the degree of diversity of land use types in each neighborhood. Five land use types were considered: residential, retail, office, institutional, and recreational. Neighborhoods (i.e. statistical sectors) were characterized as low walkable or high walkable, based on the median.

\section{Analyses}

Descriptive characteristics of the sample were analyzed using SPSS20. PA variables were logarithmically transformed $(\log 10)$ to improve normality. Linear regression analyses were conducted in MLwiN2.25. Multilevel modeling was used to take into account clustering of children within classes within schools; and schools, classes and neighborhoods were treated as cross-classified. Model parameter estimates were obtained via Markov Chain Monte Carlo (MCMC) procedures applying an orthogonal parameterization [28].

To test the interaction between neighborhood walkability and neighborhood SES, the cross-product term of both variables was included in the models. When a significant interaction was found; separate models were fitted for high and low SES neighborhoods. All analyses were controlled for family SES, sex, age of the child and accelerometer wear time if relevant. P-values $\leq 0.05$ were considered as significant with exception for the interaction terms where it was set at $\mathrm{p} \leq 0.1$. Higher significance levels are used for interaction terms as they have less power [29]. 95\% confidence intervals (=CI) were reported.

\section{Results}

\section{Descriptive results}

Of the participating children; $45.1 \%$ were boys and $37.1 \%$ had a low family SES. The mean age of the sample was $10.9 \pm 0.9$ years. Children walked on average $6.6 \pm$ $11.6 \mathrm{mins} /$ day for transportation, cycled $4.7 \pm 9.1 \mathrm{mins} /$ day for transportation, engaged in active transportation to school for $5.1 \pm 7.7 \mathrm{mins} /$ day and engaged in sports for $20.2 \pm 20.2 \mathrm{mins} /$ day. Children engaged on average for $60.2 \pm 23.5 \mathrm{mins} /$ weekday and $50.0 \pm 30.6 \mathrm{mins} /$ weekend 
day in objective MVPA. In the sample, $59.4 \%$ of the children with low neighborhood SES and 79.3\% of the children with high neighborhood SES were member of a sports club. PA levels by neighborhood walkability and SES are presented in Table 1.

\section{Associations between neighborhood walkability, neighborhood SES and PA}

A significant interaction between neighborhood walkability and neighborhood SES was found in relation to walking for transportation during leisure time $(\beta=-0.251 \pm 0.126$; $95 \% \mathrm{CI}=-0.498,-0.004$ ) (Table 2). In low SES neighborhoods, walkability was positively related to walking for transportation during leisure time $(\beta=0.381 \pm 0.124$; $95 \% \mathrm{CI}=0.138,0.624)$ whereas in high SES neighborhoods, walkability was unrelated to walking for transportation during leisure time $(\beta=0.130 \pm 0.087 ; 95 \% C I=-0.582$, 0.562 ) (Figure 1). In the relation between walkability and sports during leisure time, a significant moderating effect of neighborhood SES was found $(\beta=0.297 \pm 0.152$; $95 \% \mathrm{CI}=-0.001,0.595$ ) (Figure 2 ). In low SES neighborhoods, walkability was negatively related to sports during leisure time $(\beta=-0.245 \pm 0.121 ; 95 \% \mathrm{CI}=-0.482,-0.008)$; whereas in high SES neighborhoods walkability was unrelated to sports during leisure time $(\beta=0.004 \pm 0.113$; $95 \%$ $\mathrm{CI}=-0.217$ and 0.225$)$. No other interaction effects were found (Table 2).

Neighborhood walkability was unrelated to weekend day accelerometer-MVPA $(\beta=0.103 \pm 0.064 ; 95 \% \mathrm{CI}=-0.022$ and 0.228 , and neighborhood SES was positively related to weekend day accelerometer-MVPA $(\beta=0.116 \pm 0.059$; $95 \% \mathrm{CI}=0.001$ and 0.232 ). Neighborhood walkability and neighborhood SES were unrelated to cycling for transportation during leisure time, active transportation to school and weekday accelerometer-based MVPA.

\section{Associations of socio-demographic covariates with PA} Girls engaged less in sports during leisure time $(\beta=-0.213 \pm 0.055 ; 95 \% \mathrm{CI}=-0.321$ and -0.105$)$ and did less weekday MVPA $(\beta=-0.147 \pm 0.015 ; 95 \% \mathrm{CI}=-0.176$ and -0.118$)$ and weekend MVPA $(\beta=-0.076 \pm 0.029$; $95 \% \mathrm{CI}=-0.133$ and -0.019$)$ compared to boys. Family SES was negatively related to walking for transportation during leisure time $(\beta=-0.189 \pm 0.051 ; 95 \% \mathrm{CI}=-0.289$ and -0.089$)$, and positively related to sports during leisure time $(\beta=0.310 \pm 0.062 ; 95 \% \mathrm{CI}=0.188$ and 0.432$)$ and MVPA during weekend days $(\beta=0.071 \pm 0.033 ; 95 \%$ $\mathrm{CI}=0.006$ and 0.136 ) (Table 2).

\section{Discussion}

The aim of this study was to investigate the association between objectively measured neighborhood walkability and children's PA and the possible moderating effects of neighborhood SES in this association. As the moderating effect of neighborhood SES affects the direct relation between neighborhood walkability and children's physical activity, the moderating effects will be discussed first.

Two significant moderating effects of neighborhood SES were found. The positive relation between walkability and walking for transportation during leisure was only present in low SES neighborhoods. It is assumed that children living in high SES neighborhoods have more access to motorized transport, and are therefore less dependent on the walkability of their neighborhood; whereas children from low SES neighborhoods may have less access to motorized transport and these children

Table 1 Descriptive characteristics of the sample by neighborhood walkability and SES

\begin{tabular}{|c|c|c|c|c|c|}
\hline \multirow[t]{2}{*}{ Variable } & \multirow[b]{2}{*}{ TOTAL GROUP } & \multicolumn{2}{|c|}{ High neighborhood walkability } & \multicolumn{2}{|c|}{ Low neighborhood walkability } \\
\hline & & Low SES $n=197$ & High SES $n=48$ & Low SES $n=48$ & High SES $n=201$ \\
\hline Age (years $\pm S D$ ) & $10.09 \pm 0.9$ & $11.01 \pm 0.9$ & $11.01 \pm 0.9$ & $10.96 \pm 1.0$ & $10.81 \pm 0.9$ \\
\hline Sex (\% boys) & 45.1 & 46.7 & 45.8 & 50.0 & 42.3 \\
\hline Family SES (\% low SES) & 37.1 & 51.1 & 20.8 & 42.6 & 26.4 \\
\hline FPAQ & mean \pm SD mins/day & mean \pm SD mins/day & mean \pm SD mins/day & mean \pm SD mins/day & mean \pm SD mins/day \\
\hline Walking during leisure time & $6.6 \pm 11.6$ & $11.3 \pm 14.0$ & $4.6 \pm 9.3$ & $3.5 \pm 7.9$ & $3.3 \pm 8.1$ \\
\hline Cycling during leisure time & $4.7 \pm 9.1$ & $5.0 \pm 9.8$ & $5.3 \pm 10.2$ & $3.9 \pm 5.5$ & $4.6 \pm 8.9$ \\
\hline Active transportation to school & $5.1 \pm 7.7$ & $5.7 \pm 8.6$ & $4.8 \pm 8.8$ & $3.7 \pm 6.3$ & $4.8 \pm 7.2$ \\
\hline Sports during leisure time & $20.2 \pm 20.2$ & $16.2 \pm 19.1$ & $22.1 \pm 18.2$ & $25.4 \pm 24.4$ & $22.4 \pm 20.1$ \\
\hline \multicolumn{6}{|l|}{ Accelerometer } \\
\hline MVPA on a weekday & $60.2 \pm 23.5$ & $56.0 \pm 23.2$ & $64.2 \pm 24.2$ & $63.6 \pm 19.7$ & $60.3 \pm 24.3$ \\
\hline MVPA on a weekend day & $50.0 \pm 30.6$ & $47.1 \pm 26.8$ & $54.8 \pm 32.8$ & $41.5 \pm 24.1$ & $53.6 \pm 33.9$ \\
\hline
\end{tabular}

$\mathrm{SD}=$ standard deviation.

SES = socio- economic status.

MVPA = moderate- to vigorous-intensity physical activity

$\mathrm{FPAQ}=$ Flemish physical activity questionnaire. 
Table 2 Associations between SES, walkability and physical activity

\begin{tabular}{|c|c|c|c|c|c|c|}
\hline & $\begin{array}{l}\text { Walking for } \\
\text { transportation } \\
\text { during leisure time }\end{array}$ & $\begin{array}{l}\text { Cycling for } \\
\text { transportation } \\
\text { during leisure time }\end{array}$ & $\begin{array}{l}\text { Active transportation } \\
\text { to school }{ }^{\mathrm{a}}\end{array}$ & $\begin{array}{l}\text { Sports during } \\
\text { leisure time } \mathrm{a}^{\mathrm{a}}\end{array}$ & $\begin{array}{l}\text { MVPA on a } \\
\text { weekday }^{\mathrm{a}, \mathrm{b}}\end{array}$ & $\begin{array}{l}\text { MVPA on a } \\
\text { weekend day }{ }^{a, b}\end{array}$ \\
\hline & $\begin{array}{l}n=473 \\
\beta \pm S E\end{array}$ & $\begin{array}{l}n=474 \\
\beta \pm S E\end{array}$ & $\begin{array}{l}n=472 \\
\beta \pm S E\end{array}$ & $\begin{array}{l}n=474 \\
\beta \pm S E\end{array}$ & $\begin{array}{l}n=432 \\
\beta \pm S E\end{array}$ & $\begin{array}{l}n=397 \\
\beta \pm S E\end{array}$ \\
\hline Sex $($ ref $=$ boy $)$ & $0.019 \pm 0.044$ & $-0.067 \pm 0.046$ & $0.036 \pm 0.048$ & $-0.213 \pm 0.055^{* *}$ & $-0.147 \pm 0.015^{* *}$ & $-0.076 \pm 0.029^{*}$ \\
\hline Age & $0.004 \pm 0.028$ & $0.038 \pm 0.027$ & $0.048 \pm 0.030$ & $0.011 \pm 0.033$ & $-0.019 \pm 0.010$ & $-0.027 \pm 0.018$ \\
\hline Family SES (ref = low) & $-0.189 \pm 0.051^{* *}$ & $0.031 \pm 0.051$ & $0.001 \pm 0.055$ & $0.310 \pm 0.062^{* *}$ & $0.031 \pm 0.017$ & $0.071 \pm 0.033^{*}$ \\
\hline $\begin{array}{l}\text { Neighborhood } \\
\text { walkability (ref = low) }\end{array}$ & $0.363 \pm 0.096^{* *}$ & $-0.040 \pm 0.096$ & $0.009 \pm 0.107$ & $-0.267 \pm 0.113^{*}$ & $-0.036 \pm 0.034$ & $0.103 \pm 0.064$ \\
\hline $\begin{array}{l}\text { Neighborhood SES } \\
\text { (ref = low) }\end{array}$ & $-0.051 \pm 0.090$ & $-0.016 \pm 0.094$ & $0.059 \pm 0.097$ & $-0.017 \pm 0.109$ & $-0.037 \pm 0.031$ & $0.116 \pm 0.059^{*}$ \\
\hline $\begin{array}{l}\text { Neighborhood } \\
\text { walkability * } \\
\text { neighborhood SES }\end{array}$ & $-0.251 \pm 0.126^{*}$ & $0.035 \pm 0.131$ & $0.070 \pm 0.142$ & $0.297 \pm 0.152\left(^{*}\right)$ & $0.051 \pm 0.043$ & $-0.068 \pm 0.082$ \\
\hline
\end{tabular}

$\left({ }^{*}\right) 0.05<\mathrm{p}<0.10,{ }^{*} \mathrm{p}<0.05,{ }^{* *} \mathrm{p}<0.001$.

${ }^{\mathrm{a}}=$ logarithmically transformed.

${ }^{b}=$ controlled for accelerometer wear time.

$\mathrm{n}=$ number of children in the analytical sample.

$\beta=$ multilevel linear regression coefficient.

$\mathrm{SE}=$ standard error.

walk more for transportation during leisure time in a high walkable neighborhood, when a lot of destinations are nearby. However, this moderating effect was not found for active transportation to school. It is possible that both children from high and low SES neighborhoods go to school actively, as the prevalence of active commuting in Belgian children is high $(59.3 \%$ actively commutes to school) [30], possibly because most of children live close to their school [30]. Therefore, children's active transportation to school is probably independent of the neighborhood walkability and SES in Belgium.

Neighborhood SES also moderated the relation between walkability and sports during leisure time. In low
SES neighborhoods, children engaged more in sports in low walkable neighborhoods and less in high walkable neighborhoods; whereas in high SES neighborhoods, walkability was unrelated to sports. It has been shown previously that SES was positively associated with sports club membership [31]. As children from high SES neighborhoods are more frequently a member of a sports club; the characteristics of their neighborhood are probably less important in order to be active. Because children from low SES neighborhoods do not always have the opportunity to be member of a sports club, due to high costs [32] and lack of parental support, they probably engage more in unorganized forms of PA such as

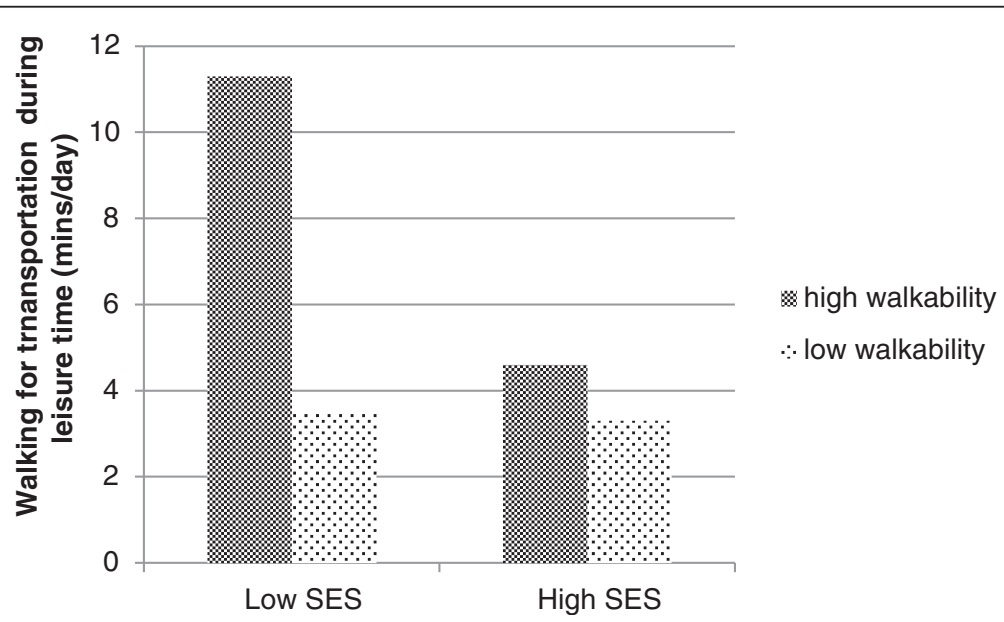

Figure 1 Moderating effect of neighborhood SES in the relation between neighborhood walkability and walking for transportation. 


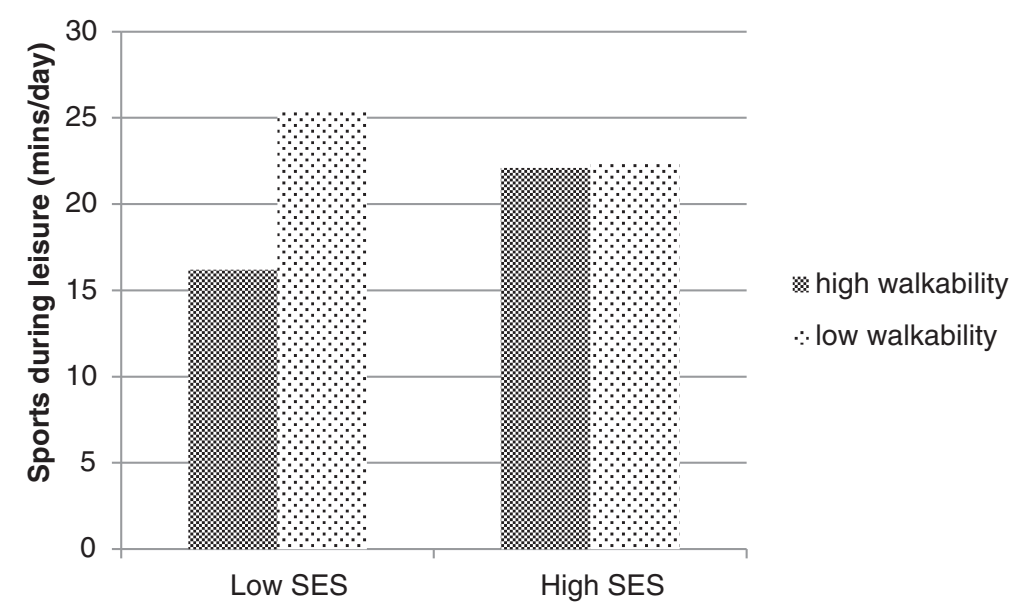

Figure 2 Moderating effect of neighborhood SES in the relation between neighborhood walkability and sports during leisure time.

active street play (e.g. playing street soccer,..). In an Australian study, safety, living in a dead-end street and public open spaces were positively associated with children's play [33]. Also in the USA [34] and Canada [35] children were more active in their neighborhood when low street connectivity was perceived (e.g. more deadend streets). As these environmental factors are mainly characteristics of a low walkable neighborhood, this may explain the negative relation between walkability and sports during leisure time in low SES neighborhoods.

The fact that children from high SES are more frequently member of a sports club [31], may also explain the positive relation between neighborhood SES and children's weekend MVPA and between family SES and sports during leisure time. However this relation was not found for weekday MVPA. As children's weekday MVPA is highly dependent on the MVPA of children during the school day, it could be expected that children's SES or walkability was unrelated to their weekday MVPA. Furthermore, no effects of walkability or neighborhood SES were found on children's MVPA. These results show that environmental factors are differently related to specific domains of PA, which argues for investigating the relation between the environment and PA for different domains of PA, rather than investigating this in relation to overall MVPA or total PA [36].

Different relations between the environment and PA were found across different age groups in the same city $[9,13,14]$. But similar as in Belgian adolescents in the same city, we found a stronger relation between neighborhood walkability and PA in low SES neighborhoods [14]. However, there is no univocal relation between neighborhood walkability and children's PA. Living in a high walkable neighborhood can be beneficial for walking for transportation during leisure time, but is negatively associated with sports during leisure time in low-SES neighborhoods. Therefore, based on the present findings the positive and promising results from the adult studies cannot be generalized to children [8-10]. This raises the question whether the walkability index, should be changed into a "playability" or "movability" index in order to be relevant to explain children's PA, as it is possible that other environmental variables (e.g. open spaces and dead end streets), are more important. This implies that physical environmental interventions targeted to increase PA in adults may have opposite effects in children, so attention should be paid when intervening in the physical environment. Children must have the opportunity to play outside and to be active in their neighborhood, especially in low SES and high walkable neighborhoods. Therefore, future interventions should focus on economically disadvantaged subgroups. This may be done by providing play space for children from low SES neighborhoods, e.g. by the provision of sport fields or play streets.

Also the relation between environmental parental perceptions and children's PA needs to be investigated. As parents are seen as the decision makers for their children [37], it is possible that parental environmental perceptions are more strongly related to children's PA.

A strength of this study is the use of objectively measured walkability, as objective measures have less measurement error compared to perceptions [38]. Furthermore, the relation between walkability and PA was measured objectively and subjectively. The cross-sectional character of the study is a limitation, as no causal relationships can be examined. Second, statistical sectors were used to define neighborhoods. It is possible that the investigated neighborhood was not the neighborhood that children and parents would define as 'their own neighborhood'. Also the low response rate of the school principals is a limitation of this study. Furthermore, data were collected in one city, which may limit the generalizability of the findings. Also, 
children were recruited in schools instead of neighborhoods with varying walkability and SES levels. This led to the inclusion of children living mostly in high SES-low walkable or low SES-high walkable neighborhoods; children living in low SES-low walkable and high SES-high walkable neighborhoods were underrepresented. Besides, it needs to be acknowledged that it is very difficult to point out the exact relation between physical environmental factors and physical activity, because of the strong interaction between environmental, social and individual factors. Therefore, in future research, the moderating effect of other factors (e.g. family type, number of siblings) in the relation between walkability and children's physical activity should be investigated.

\section{Conclusions}

No univocal relation between walkability and PA was found in children. In low SES neighborhoods, children walked more for transportation during leisure time and engaged in less sports during leisure time in high walkable neighborhoods compared to low walkable neighborhoods. In high SES neighborhoods, walkability was unrelated to children's PA. Results from international adult studies cannot be generalized to children.

\section{Additional file}

Additional file 1: Outline of the FPAQ questionnaire.

\section{Abbreviations}

MVPA: Moderate- to vigorous-intensity physical activity; PA: Physical activity.

\section{Competing interests}

The authors declare that they have no competing interests.

\section{Authors' contributions}

All authors helped to develop the data collection protocol. SDH coordinated the data collection and conducted the statistical analyses and drafted the manuscript. DVD, IDB, BD and GC participated in the interpretation of the data, helped to draft the manuscript and revised the manuscript for important intellectual content. All authors read and approved the final manuscript.

\section{Acknowledgements}

SDH and DVD were supported by Research Foundation Flanders (FWO). The authors want to thank Tine Coolen, Eva D'Hoore, Gert Lambrecht, Sarah Minten, An-Sofie Pinket, Britt Van Oost and Lieve Vanoverschelde for their assistance in data collection.

\section{Author details \\ ${ }^{1}$ Faculty of Medicine and Health Sciences, Department of Movement and Sports Sciences, Ghent University, Watersportlaan 2, Ghent 9000, Belgium. ${ }^{2}$ Research Foundation Flanders (FWO), Egmontstraat 5, Brussels 1000, Belgium. ${ }^{3}$ Department of Human Biometrics and Biomechanics, Vrije Universiteit Brussel, Brussels, Belgium.}

Received: 29 January 2014 Accepted: 8 August 2014 Published: 23 August 2014

\section{References}

1. Janssen I, Leblanc AG: Systematic review of the health benefits of physical activity and fitness in school-aged children and youth. Int J Behav Nutr Phys Act 2010, 7:40.
2. Verloigne M, Van Lippevelde W, Maes L, Yildirim M, Chinapaw M, Manios Y Androutsos O, Kovacs E, Bringolf-Isler B, Brug J, De Bourdeaudhuij I: Levels of physical activity and sedentary time among 10- to 12-year-old boys and girls across 5 European countries using accelerometers: an observational study within the ENERGY-project. Int J Behav Nutr Phys Act 2012, 9:34.

3. Baranowski T, Anderson C, Carmack C: Mediating variable framework in physical activity interventions. How are we doing? How might we do better? Am J Prev Med 1998, 15:266-297.

4. Sallis JF, Owen N, Fisher EB: Ecological Models of Health Behavior. In Health Behavior and Health Education. 4th edition. Edited by Glanz K, Rimer BK, Viswanath K. United States of America: John Wiley and Sons; 2008:465-485.

5. Kremers SP, de Bruijn GJ, Visscher TL, Van MW, de Vries NK, Brug J: Environmental influences on energy balance-related behaviors: a dual-process view. Int J Behav Nutr Phys Act 2006, 3:9.

6. Grasser G, Van DD, Titze S, Stronegger W: Objectively measured walkability and active transport and weight-related outcomes in adults: a systematic review. Int J Public Health 2013, 58:615-625.

7. Saelens BE, Sallis JF, Frank LD: Environmental correlates of walking and cycling: findings from the transportation, urban design, and planning literatures. Ann Behav Med 2003, 25:80-91.

8. Sallis JF, Saelens BE, Frank LD, Conway TL, Slymen DJ, Cain KL, Chapman JE, Kerr J: Neighborhood built environment and income: examining multiple health outcomes. Soc Sci Med 2009, 68:1285-1293.

9. Van Dyck D, Cardon G, Deforche B, Sallis JF, Owen N, De Bourdeaudhuij I: Neighborhood SES and walkability are related to physical activity behavior in Belgian adults. Prev Med 2010, 50(1):S74-S79.

10. Owen N, Cerin E, Leslie E, DuToit L, Coffee N, Frank LD, Bauman AE, Hugo G, Saelens BE, Sallis JF: Neighborhood walkability and the walking behavior of Australian adults. Am J Prev Med 2007, 33:387-395.

11. Sundquist K, Eriksson U, Kawakami N, Skog L, Ohlsson H, Arvidsson D: Neighborhood walkability, physical activity, and walking behavior: the Swedish Neighborhood and Physical Activity (SNAP) study. Soc Sci Med 2011, 72:1266-1273.

12. Winkleby MA, Jatulis DE, Frank E, Fortmann SP: Socioeconomic status and health: how education, income, and occupation contribute to risk factors for cardiovascular disease. Am J Public Health 1992, 82:816-820.

13. Van Holle V, Van Cauwenberg J, Van Dyck D, Deforche B, Van de Weghe N, De Bourdeaudhuij I: Relationship between neighborhood walkability and older adults' physical activity: results from the Belgian Environmental Physical Activity Study in Seniors (BEPAS Seniors). International Journal of Behavioral Nutrition and Physical Activity 2014, 11:110.

14. De Meester F, Van Dyck D, De Bourdeaudhuij I, Deforche B, Sallis JF, Cardon G: Active living neighborhoods: is neighborhood walkability a key element for Belgian adolescents? BMC Public Health 2012, 12:7.

15. Christiansen LB, Toftager M, Schipperijn J, Ersboll AK, Giles-Corti B, Troelsen J: School site walkability and active school transport - association, mediation and moderation. J Transp Geogr 2014, 34:7-15.

16. Trapp GS, Giles-Corti B, Christian HE, Bulsara M, Timperio AF, McCormack GR, Villaneuva KP: On your bike! a cross-sectional study of the individual, social and environmental correlates of cycling to school. Int J Behav Nutr Phys Act 2011, 8:123.

17. Giles-Corti B, Wood G, Pikora T, Learnihan V, Bulsara M, Van NK, Timperio A, McCormack G, Villanueva K: School site and the potential to walk to school: the impact of street connectivity and traffic exposure in school neighborhoods. Health Place 2011, 17:545-550.

18. Holt NL, Spence JC, Sehn ZL, Cutumisu N: Neighborhood and developmental differences in children's perceptions of opportunities for play and physical activity. Health Place 2008, 14:2-14.

19. Kerr J, Rosenberg D, Sallis JF, Saelens BE, Frank LD, Conway TL: Active commuting to school: Associations with environment and parental concerns. Med Sci Sports Exerc 2006, 38:787-794.

20. Shavers VL: Measurement of socioeconomic status in health disparities research. J Natl Med Assoc 2007, 99:1013-1023.

21. Verstraete S, De Bourdeaudhuij I, Cardon G: Validation of a physical activity questionnaire for children. Med Sci Sports Exerc 2003, 5:S337.

22. Robusto KM, Trost SG: Comparison of three generations of ActiGraph activity monitors in children and adolescents. J Sports Sci 2012, 30:1429-1435.

23. De Meester F, De Bourdeaudhuij I, Deforche B, Ottevaere C, Cardon G: Measuring physical activity using accelerometry in 13-15-year-old 
adolescents: the importance of including non-wear activities. Public Health Nutr 2011, 14:2124-2133.

24. Evenson KR, Catellier DJ, Gill K, Ondrak KS, McMurray RG: Calibration of two objective measures of physical activity for children. J Sports Sci 2008, 26:1557-1565.

25. Trost SG, Loprinzi PD, Moore R, Pfeiffer KA: Comparison of accelerometer cut points for predicting activity intensity in youth. Med Sci Sports Exerc 2011, 43:1360-1368.

26. Mattocks C, Ness A, Leary S, Tilling K, Blair SN, Shield J, Deere K, Saunders J, Kirkby J, Smith GD, Wells J, Wareham N, Reilly J, Riddoch C: Use of accelerometers in a large field-based study of children: protocols, design issues, and effects on precision. J Phys Act Health 2008, 5(Suppl 1):S98-111.

27. Frank LD, Sallis JF, Saelens BE, Leary L, Cain K, Conway TL, Hess PM: The development of a walkability index: application to the Neighborhood Quality of Life Study. Br J Sports Med 2010, 44:924-933.

28. Browne WJ: MCMC Estimation in MLwiN v2.26. Centre for Multilevel Modelling, University of Bristol. 2012. http://www.bristol.ac.uk/cmm/software/m/win/ refs.html.

29. Twisk J: Applied Multilevel Analysis. Cambridge: Cambridge University Press; 2006

30. D'Haese S, De Meester F, De Bourdeaudhuij I, Deforche B, Cardon G: Criterion distances and environmental correlates of active commuting to school in children. Int J Behav Nutr Phys Act 2011, 8:88.

31. Vandendriessche JB, Vandorpe BF, Vaeyens R, Malina RM, Lefevre J, Lenoir M, Philippaerts RM: Variation in sport participation, fitness and motor coordination with socioeconomic status among Flemish children. Pediatr Exerc Sci 2012, 24:113-128.

32. Sallis JF, Zakarian JM, Hovell MF, Hofstetter CR: Ethnic, socioeconomic, and sex differences in physical activity among adolescents. J Clin Epidemiol 1996, 49:125-134.

33. Veitch J, Salmon J, Ball K: Individual, social and physical environmental correlates of children's active free-play: a cross-sectional study. Int $J$ Behav Nutr Phys Act 2010, 7:11.

34. Tappe KA, Glanz K, Sallis JF, Zhou C, Saelens BE: Children's physical activity and parents' perception of the neighborhood environment: neighborhood impact on kids study. Int J Behav Nutr Phys Act 2013, 10:39.

35. Mecredy G, Janssen I, Pickett W: Neighbourhood street connectivity and injury in youth: a national study of built environments in Canada. Inj Prev 2012, 18:81-87.

36. Giles-Corti B, Timperio A, Bull F, Pikora T: Understanding physical activity environmental correlates: increased specificity for ecological models. Exerc Sport Sci Rev 2005, 33:175-181.

37. Panter JR, Jones AP, van Sluijs EM: Environmental determinants of active travel in youth: a review and framework for future research. Int I Behav Nutr Phys Act 2008, 5:34.

38. Ding D, Sallis JF, Kerr J, Lee S, Rosenberg DE: Neighborhood environment and physical activity among youth a review. Am J Prev Med 2011 41:442-455.

doi:10.1186/s12966-014-0104-1

Cite this article as: D'Haese et al:: The association between objective walkability, neighborhood socio-economic status, and physical activity in Belgian children. International Journal of Behavioral Nutrition and Physical Activity 2014 11:104.

\section{Submit your next manuscript to BioMed Central and take full advantage of:}

- Convenient online submission

- Thorough peer review

- No space constraints or color figure charges

- Immediate publication on acceptance

- Inclusion in PubMed, CAS, Scopus and Google Scholar

- Research which is freely available for redistribution

Submit your manuscript at www.biomedcentral.com/submit
C Biomed Central 